\title{
Endovascular and Microsurgical Treatment of Superior Cerebellar Artery Aneurysms
}

\author{
Sung-Chul Jin, $M D^{1}$, Eun Suk Park, $M D^{2}$, Do Hoon Kwon, $M D^{2}$, \\ Jae Sung Ahn, $M D^{2}$, Byung Duk Kwun, $\mathrm{MD}^{2}$, Chang Jin Kim, $\mathrm{MD}^{2}$, Choong-Gon Choi, $\mathrm{MD}^{3}$ \\ Department of Neurosurgery ${ }^{l}$, Haeundae Paik Hospital, Inje University, Pusan, Korea \\ Department of Neurological Surgery ${ }^{2}$ and Radiology ${ }^{3}$, Asan Medical Center, College of Medicine,
}

University of Ulsan, Seoul, Korea

\begin{abstract}
Objective: Superior cerebellar artery (SCA) aneurysms are regarded as being as difficult to treat surgically as posterior circulation aneurysms. We describe here a series of 33 of these aneurysms treated with microsurgery or embolization. Methods: Between June 1997 and August 2007, 33 patients (9 men, 24 women; age, 29 to 76 years) with SCA aneurysms underwent microsurgical $(n=12)$ or endovascular $(n=21)$ treatment. Twenty two patients presented with subarachnoid hemorrhage. Thirty aneurysms were located in the junction between the SCA and the basilar artery (BA), two in the proximal SCA (S1) and one in the distal SCA (S2-3). Results: Of the 29 SCA aneurysms, located in the junction between the SCA and $\mathrm{BA}$, which were available on conventional angiography, 20 were lateral-superior, six lateral-horizontal, two lateral inferior, and one posterior type. Of the 12 patients treated microsurgically, eight had clinically excellent or good outcomes. Causes of poor outcomes included initial poor clinical status $(n=2)$, infarction due to parent artery compromise $(\mathrm{n}=1)$, and artery of Heubner injury due to surgery for a coexisting anterior communicating artery aneurysm $(n=1)$. Of the 21 patients treated endovascularly, 17 had clinical good or excellent outcomes. Causes of clinically poor outcomes included initial poor clinical status $(n=2)$ and infarction due to thrombosis of exposed coil mesh $(n=1)$. One patient underwent embolization resulted in death due to vasospasm. Three patients required additional embolization for coil compaction. Conclusions: There was no morbidity related to perforator injury, regardless of the treatment modality. Embolization or microsurgery is an effective modality, with relatively low procedural morbidity and mortality rates.
\end{abstract}

(J Cerebrovasc Endovasc Neurosurg. 2012 Mar;14(1):29 36)

KEY WORDS Aneurysm·Endovascular - Microsurgery - Superior cerebellar artery

\section{INTRODUCTION}

Received : 12 January 2012

Revised : 13 February 2012

Accepted : 6 March 2012

Corresponding Author : Do Hoon Kwon, MD

Address : Asan Medical Center, 388-1, Poongnap-dong, Songpa-

gu, Seoul, 138-736, Korea

Tel : (001) 82-2-3010-3555 Fax : (001) 82-2-476-6738

E-mail : ykwon@amc.seoul.kr
Aneurysms located on the superior cerebellar artery (SCA) are uncommon. Clinical series of endovascular or surgical management in SCA aneurysms were usually limited in the distal segment of SCA aneurysms or incorporated in the literatures of basilar artery (BA) or posterior circulation aneurysms. ${ }^{14) 7) 10) 13-16) 18) 22) 24) 25) ~}$ Posterior circulation aneurysms including SCA aneurysms were regarded challenging to neurosurgeon due to narrow operative field, their intimate relationship to per- 
forating vessels and cranial nerves, high morbidity and morbidity rates. ${ }^{218)}$ Although endovascular treatment of SCA aneurysms has been reported to be effective and safe, ${ }^{10) 17)}$ SCA aneurysms have peculiar characteristics different from those of basilar apex aneurysms, including relatively easy surgical accessibility to the lesions using a conventional pterional approach and poor perforating arteries related to the aneurysms. We describe here our clinical experiences with endovascular and microsurgical treatment of SCA, as well as classifying SCA aneurysms by angiographic features.

\section{Materials and Methods}

Between June 1997 and August 2007, 33 patients with SCA aneurysms ( 9 men, 24 women; mean age 53.7 years; range, 29-76 years) underwent microsurgical $(n=12)$ or endovascular treatment $(\mathrm{n}=21)$ in our institution. SCA was classified into anterior mesencephalic (S1), lateral mesencephalic (S2), cerebellomesencephalic (S3), and cortical (S4) segment. ${ }^{19)}$ Of the 33 SCA aneurysms, 30 $(90.9 \%)$ were in the junction between the SCA and the
$\mathrm{BA}$, two in $\mathrm{S} 1$ and one in S2-3. Patients with SCA aneurysms plus other vascular malformations such as moyamoya disease or arteriovenous malformation were excluded from this analysis.

Of the 33 patients, 22 presented with subarachnoid hemorrhage (SAH) and one suffered from third nerve palsy due to mass effect. The aneurysms were incidentally discovered in five patients and they were associated with coexisting aneurysms in five. In 14 patients (42.4\%), we observed other aneurysms in addition to the SCA aneurysm. The 22 patients presenting with SAH were classified by the Hunt-Hess scale; ${ }^{11)}$ one patient was Grade I, nine were Grade II, six were Grade III, and seven were Grade IV.

Based on conventional angiography obtained at the time of evaluation, the morphology of SCA aneurysms were saccular in 32 patients and dissecting in one patient. Classification of these aneurysms by size and neck width showed that 15 small aneurysms were very small $(\leq 5 \mathrm{~mm})$ with a small neck $(<4 \mathrm{~mm})$; however, one was very small with a wide neck $(\geq 4 \mathrm{~mm})$, three

Table 1. Characteristics of 12 patients with SCA aneurysms underwent surgical clipping

\begin{tabular}{|c|c|c|c|c|c|c|c|c|c|c|c|}
\hline $\begin{array}{l}\text { Case } \\
\text { No }\end{array}$ & $\begin{array}{l}\text { Age }(y r s) / \\
\text { Sex }\end{array}$ & $\begin{array}{l}\text { Presentation/ } \\
\mathrm{H}-\mathrm{H} \text { grade }\end{array}$ & Location & $\begin{array}{l}\text { Aneurysm } \\
\text { Size }(\mathrm{mm})\end{array}$ & $\begin{array}{c}\text { Neck } \\
\text { Size }(m m)\end{array}$ & $\begin{array}{c}\text { SCA } \\
\text { incorporation }\end{array}$ & Classification & $\begin{array}{l}\text { Initial } \\
\text { results }\end{array}$ & complication & $\begin{array}{c}\text { GO } \\
S\end{array}$ & $\begin{array}{l}\text { Results of } \\
\text { Image FU }\end{array}$ \\
\hline 1 & $49 / F$ & asymptomatic & Junction & 4.0 & 3.0 & Yes & Lateral superior & Complete & NO & 5 & Complete \\
\hline 2 & $51 / F$ & $\mathrm{SAH} / \mathrm{III}$ & Junction & 2.0 & 1.3 & No & posterior & Complete & 3rdNervepalsy & 5 & Complete \\
\hline 3 & $72 / F$ & SAH/ III & Junction & 9.5 & 6.8 & Yes & Lateral horizontal & Complete & $\begin{array}{l}\text { PCA infarction, } \\
\text { 3rdNervepalsy }\end{array}$ & 3 & Complete \\
\hline 4 & $75 / F$ & SAH/ IV & Junction & 6.5 & 3.5 & Yes & Lateral horizontal & complete & No & 3 & N/A \\
\hline 5 & $37 / M$ & $\mathrm{SAH} / \|$ & Junction & 5.0 & 4.0 & Yes & Lateral superior & complete & 3rdnervepalsy & 5 & Complete \\
\hline 6 & $68 / F$ & asymptomatic & Junction & 12.0 & 9.3 & Yes & Lateral horizontal & Complete & $\begin{array}{c}\text { Heubner's } \\
\text { injury, } \\
\text { 3rdNervepalsy }\end{array}$ & 3 & Complete \\
\hline 7 & $65 / F$ & asymptomatic & Junction & 2.2 & 2.4 & No & Lateral superior & $\begin{array}{l}\text { Residual } \\
\text { neck }\end{array}$ & No & 5 & $\begin{array}{l}\text { Residual } \\
\text { neck }\end{array}$ \\
\hline 8 & $71 / F$ & asymptomatic & Junction & 5.2 & 3.8 & yes & Lateral superior & Complete & No & 5 & Complete \\
\hline 9 & $41 / F$ & $\mathrm{SAH} / \|$ & Junction & 15.0 & 8.0 & yes & Lateral superior & Complete & No & 5 & Complete \\
\hline $10^{*}$ & $40 / F$ & SAH/ II & Junction & 4.0 & 2.0 & yes & Lateral superior & N/A & No & 5 & N/A \\
\hline 11 & $53 / M$ & SAH/ IV & Junction & 10.0 & 5.0 & N/A & N/A & $\begin{array}{l}\text { Residual } \\
\text { sac }\end{array}$ & 3rdnervepalsy & 3 & N/A \\
\hline 12 & $73 / F$ & SAH/ III & Junction & 15.6 & 4.2 & No & Lateral superior & Complete & No & 4 & Complete \\
\hline
\end{tabular}

$\mathrm{H}-\mathrm{H}$ grade = Hunt and Hess grade; SCA = Superior Cerebellar Artery; GOS = Glasgow Outcome Scale; FU = follow-up; $F=$ female; $M=$ male; $\mathrm{SAH}=$ subarachnoid hemorrhage; PCA = Posterior Cerebral Artery; Junction = aneurysm in junction the between the Basilar Artery and SCA; N/A= not available

${ }^{*}$ A patient with a previous history of surgical clipping of another ruptured aneurysm and no definite SCA aneurysm on initial angiogram suffered from SAH four years after surgery. Conventional angiography revealed the growth of an SCA aneurysm. 
Table 2. Characteristics of 21 patients with SCA aneurysms underwent endovascular treatments.

\begin{tabular}{|c|c|c|c|c|c|c|c|c|c|c|c|}
\hline $\begin{array}{l}\text { Case } \\
\text { No }\end{array}$ & $\begin{array}{l}\text { Age(yrs) } \\
\text { /Sex }\end{array}$ & $\begin{array}{c}\text { Presentation/ } \\
\mathrm{H}-\mathrm{H} \text { grade }\end{array}$ & Location & $\begin{array}{l}\text { Aneurysm } \\
\text { Size }(\mathrm{mm})\end{array}$ & $\begin{array}{c}\text { Neck } \\
\text { Size }(\mathrm{mm})\end{array}$ & $\begin{array}{c}\text { SCA } \\
\text { incorporation }\end{array}$ & Classification & $\begin{array}{l}\text { Initial } \\
\text { results }\end{array}$ & $\begin{array}{l}\text { Procedural } \\
\text { complication }\end{array}$ & GOS & $\begin{array}{l}\text { Results of } \\
\text { Image FU }\end{array}$ \\
\hline 1 & $53 / F$ & Asymptomatic & S1 & 2.6 & 2.4 & N/A & N/A & Complete & No & 5 & $\begin{array}{l}\text { No interval } \\
\text { change }\end{array}$ \\
\hline $2^{*}$ & $48 / F$ & 3rd nerve palsy & Junction & 2.5 & 2.0 & No & Lateral superior & Complete & No & 5 & Residual sac \\
\hline 3 & $59 / M$ & Asymptomatic & Junction & 5.0 & 3.7 & No & Lateral horizontal & $\begin{array}{l}\text { Residual } \\
\text { sac }\end{array}$ & No & 5 & N/A \\
\hline 4 & $68 / M$ & $\mathrm{SAH} / \mathrm{III}$ & Junction & 4.2 & 2.3 & No & Lateral superior & $\begin{array}{l}\text { Residual } \\
\text { neck }\end{array}$ & No & 4 & N/A \\
\hline 5 & $76 / F$ & SAH/ IV & Junction & 8.0 & 4.4 & Yes & Lateral superior & Complete & No & 3 & N/A \\
\hline 6 & $64 / M$ & $\mathrm{SAH} / \mathrm{IV}$ & Junction & 6.5 & 4.5 & No & Lateral superior & $\begin{array}{l}\text { Residual } \\
\text { sac }\end{array}$ & No & 4 & $\begin{array}{l}\text { No interval } \\
\text { change }\end{array}$ \\
\hline 7 & $37 / M$ & $\mathrm{SAH} / \mathrm{IV}$ & Junction & 5.7 & 2.2 & Yes & Lateral superior & Complete & No & 4 & Residual neck \\
\hline 8 & $56 / F$ & SAH/ IV & Junction & 2.0 & 2.0 & yes & Lateral superior & Complete & No & 4 & N/A \\
\hline 9 & $42 / M$ & $\mathrm{SAH} / \mathrm{IV}$ & Junction & 5.2 & 3.2 & No & Lateral horizontal & Complete & No & 4 & N/A \\
\hline 10 & $71 / F$ & $\mathrm{SAH} / \|$ & Junction & 11.6 & 4.6 & No & Lateral horizontal & Complete & No & 5 & $\begin{array}{l}\text { No interval } \\
\text { change }\end{array}$ \\
\hline 11 & $29 / M$ & $\mathrm{SAH} / \|$ & Junction & 3.8 & 2.8 & No & Lateral inferior & Complete & No & 5 & $\begin{array}{l}\text { No interval } \\
\text { change }\end{array}$ \\
\hline 12 & $36 / F$ & $\mathrm{SAH} / \|$ & S2-3 & N/A & N/A & N/A & N/A & Complete & No & 5 & $\begin{array}{l}\text { No interval } \\
\text { change }\end{array}$ \\
\hline 13 & $29 / F$ & $\mathrm{SAH} / \|$ & Junction & 1.8 & 1.6 & No & Lateral superior & Complete & No & 5 & $\begin{array}{l}\text { No interval } \\
\text { change }\end{array}$ \\
\hline 14 & $50 / F$ & $\mathrm{SAH} / \|$ & Junction & 10.2 & 5.2 & No & Lateral superior & Complete & No & 5 & $\begin{array}{l}\text { No interval } \\
\text { change }\end{array}$ \\
\hline $15^{*}$ & $61 / F$ & Asymptomatic & Junction & 11.4 & 4.3 & No & Lateral superior & $\begin{array}{l}\text { Residual } \\
\text { neck }\end{array}$ & No & 5 & Residual neck \\
\hline $16^{*}$ & $45 / M$ & $\mathrm{SAH} / \mathrm{III}$ & Junction & 7.7 & 4.6 & Yes & Lateral inferior & $\begin{array}{l}\text { Residual } \\
\text { neck }\end{array}$ & No & 5 & Residual neck \\
\hline 17 & $44 / F$ & Asymptomatic & Junction & 4.0 & 2.3 & Yes & Lateral superior & $\begin{array}{l}\text { Residual } \\
\text { sac }\end{array}$ & No & 5 & N/A \\
\hline 18 & $51 / F$ & $\mathrm{SAH} / \mathrm{II}$ & Junction & 14.4 & 7.2 & Yes & Lateral superior & $\begin{array}{l}\text { Residual } \\
\text { neck }\end{array}$ & No & 1 & \\
\hline $19^{\dagger}$ & $64 / F$ & $\mathrm{SAH} / \mathrm{I}$ & S1 & 3.0 & 2.0 & N/A & N/A & $\begin{array}{l}\text { Residual } \\
\text { sac }\end{array}$ & $\begin{array}{l}\text { thromboemb } \\
\text { olism }\end{array}$ & 3 & N/A \\
\hline $20^{\dagger}$ & $53 / F$ & $\mathrm{SAH} / \mathrm{III}$ & Junction & 2.6 & 2.4 & Yes & Lateral superior & $\begin{array}{l}\text { Residual } \\
\text { neck }\end{array}$ & No & 4 & N/A \\
\hline 21 & $44 / F$ & Asymptomatic & Junction & 6.0 & 4.0 & No & Lateral superior & Complete & No & 5 & $\begin{array}{l}\text { No interval } \\
\text { change }\end{array}$ \\
\hline
\end{tabular}

S1= anterior mesencephalic segment; S2 = lateral mesencephalic segment; S3=cerebellomesencephalic segment.

*Patients underwent repeated coil embolization due to recanalization of the coiled aneurysms.

${ }^{\dagger}$ Patient presented with SAH and no definite SCA aneurysm. Short-term angiographic follow-up revealed the prominent growth of an SCA aneurysm.

were $>5 \mathrm{~mm}$ and $<10 \mathrm{~mm}$ in diameter with a small neck, six were small with wide necks, and seven were large $(\geq 10 \mathrm{~mm})$ with wide necks.

Due to the loss of conventional radiography results in one patient, the detailed subtypes of SCA aneurysms could be classified only for 32 patients. Patients with SCA aneurysms in the junction between SCA and BA were categorized according to the main direction of the aneurysm sac and by the angle between the BA and an imaginary line from the center of the aneurysm sac to the mid-point of the neck as having lateral (angle $>105$ degrees), 2) lateral horizontal (angle $\geq 90$ degrees, $\leq 105$ degrees), 3) lateral inferior (angle $<90$ degrees), and 4) posterior SCA aneurysms.

The decision as to whether to treat surgically or by other methods was discussed among the physicians, including neurovascular surgeons and neurointerventionists. Factors indicating treatment of unruptured aneurysms in- 
cluded 1) multiple aneurysms $(\mathrm{n}=5), 2)$ bleb formation $(n=3), 3)$ large aneurysm $(n=2)$, and cranial nerve palsy $(n=1)$. Indications for microsurgery included anticipated endovascular difficulty because of aneurysm size or morphology $(n=11)$ and attempted embolization $(n=1)$. Indications for endovascular treatment included 1) poor neurological status $(\mathrm{m}=5) ; 2)$ expected difficulty of surgical access due to aneurysm location or morphological characteristics $(n=5)$; 3) morphological characteristics indicating embolization $(\mathrm{n}=8) ; 4)$ attempted microsurgery $(\mathrm{n}=1) ; 5)$ the need for an alternative to microsurgery due to previous surgical clipping for other coexisting aneurysms $(n=1)$; and 6) embolization trial $(n=1)$.

Aneurysms were evaluated by computed tomographic angiography (CTA) immediately after surgical clipping. CTA was performed annually after microsurgery if the lesions had been completely occluded. CTA was recommended three months after surgical clipping in patients with residual aneurysms. Follow-up time of flight magnetic resonance angiography (MRA) was performed six months after embolization if the lesions had been completely occluded. MRA was recommended three months after embolization in patients with incompletely embolized aneurysms. Subsequent follow-up MRA was performed annually in patients with no interval changes compared with the previous evaluation. Conventional angiography was used to confirm coil compaction or regrowth of the aneurysm in patients with progression of incompletely occluded aneurysms.

Radiological results without relationship to treatment alternatives included complete obliteration, residual neck and residual aneurysms. ${ }^{20) 21)}$ Complete occlusion was defined as a complete absence of contrast agent filling of the aneurysms following embolization or microsurgery on conventional angiography or CTA, residual neck was defined as lesions with residual filling of part of the neck, and residual sac was defined as incomplete occlusion of the aneurysm sac because of partial filling of the coils or incomplete surgical clipping.

Patients were clinically followed-up mainly at out-pa- tient clinical visits or by telephone interviews.

Clinical outcomes were evaluated according to the Glasgow Outcome Scale (GOS).

\section{RESULTS}

In classifying these 29 patients with SCA aneurysms in the junction between the BA and the SCA, based on our angiographic data we found that 20 patients $(69.0 \%)$ had lateral-superior aneurysms. In addition, six patients $(20.7 \%)$ had lateral-horizontal, two $(6.9 \%)$ had lateral-inferior, and one (3.4\%) had a posterior SCA (Fig. 1).

Three patients with SAH showed aneurysm growth. One patient, who presented with $\mathrm{SAH}$, had a suspected SCA aneurysm and no coexisting aneurysms on initial conventional angiogram. Follow-up angiogram two weeks after ictus revealed growth of the aneurysm sac. Rupture of a middle cerebral artery (MCA) aneurysm was suggested in one patient with multiple aneurysms, of which the S1 aneurysm was not prominent on initial angiogram. No rupture point of the MCA aneurysm was detected on microsurgery. Conventional angiograms four days after surgery revealed remarkable growth of the S1 aneurysm. One patient, with a previous history of surgical clipping of another ruptured aneurysm and no definite SCA aneurysm on initial angiogram, suffered from SAH four years after surgery, with conventional angiography showing that the SCA aneurysm had grown.

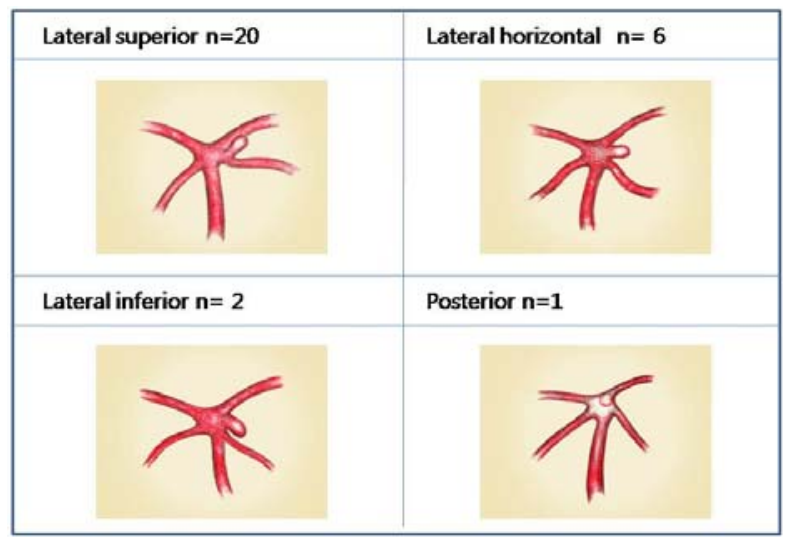

Fig. 1. Classification of Superior Cerebellar Artery (SCA) aneurysm according to angiographic features. 
Of the 12 patients treated microsurgically, nine showed complete occlusion. In contrast, residual neck was observed in one patient, residual sac in one patient, and the residual status was not evaluated in one patient who underwent simple brain CT due to a poor neurological condition. Nine patients underwent follow-up radiological evaluation with a mean of 33.3 months (range 3-84 months). Causes of loss to radiological follow-up included poor neurological status in two patients and poor compliance in one patient. All patients who underwent radiological follow-up had no evidence of aneurysm regrowth or recurrence. Clinical outcome at discharge in patients who underwent microsurgery included GOS 5 in seven patients, GOS 4 in one and GOS 3 in four. Reasons for poor neurological outcome included 1) initially poor neurological condition without improvement $(n=2), 2)$ injury to the recurrent artery of Heubner due to surgical clipping of coexisting anterior communicating artery aneurysm $(\mathrm{n}=1)$, and 3$)$ occipital infarction due to compromise of PCA $(n=1)$. Operation related morbidities included third nerve palsy in five patients, with most showing gradual recovery, Huebner's injury in one patient, and parent vessel compromise in one patient. Clinical follow-up was available for 11 patients at 3 to 84 months (mean, 28.8 months). Clinical follow-up included GOS 5 in eight patients, GOS 4 in one, and GOS 3 in two.

Of the 21 patients treated endovascularly, 20 with saccular SCA aneurysms showed occlusion of the aneurysm using a coil, whereas one patient with S2-3 dissecting aneurysm was treated by parent artery occlusion using a coil. Angiographic results of patients treated with embolization demonstrated complete occlusion in 12 patients $(57.1 \%)$, residual neck in five $(23.8 \%)$, and residual sac in four (19.0\%). Twelve patients $(60.0 \%)$ underwent follow-up radiological evaluations at a mean 35.7 months after treatment (range, 3-79 months). Reasons for loss to radiological follow-up included 1) clinical severe vasospasm-induced mortality $(n=1), 2)$ transfer to other hospitals $(n=2), 3)$ poor neurological status $(n=2)$, and 4$)$ poor compliance $(n=4)$. Four patients with complete occlusion $(n=2)$ or residual neck $(n=2)$ were demonstrated coil compaction or further recanalization of the aneurysm. Additional embolization was performed in three patients with significant progressive coil compaction or recanalization of the aneurysm. Procedure related complications developed in one patient with symptomatic thromboembolism. Clinical outcomes at discharge in patients who underwent embolization included GOS 5 in 12 patients, GOS 4 in six, GOS 3 in two, and GOS 1 in one patient. A 76-year-old female patient presenting with Hunt-Hess grade IV underwent external ventricular drainage and subsequent coil embolization. The patient did not recover and developed ventriculitis resulting in GOS 3. Another 64 year-old female patient presenting with Hunt and Hess grade I underwent surgical clipping of an MCA aneurysm that was not ruptured on surgical assessment. Follow-up angiogram four days after microsurgery revealed growth of an $\mathrm{S} 1$ aneurysm (size, $3 \mathrm{~mm}$ ), previously thought not to be a definite aneurysm. Coil embolization resulted in PCA and SCA territory infarction opposite to embolization lesion, due mainly to a hypercoagulation period after microsurgery and partial coil exposure. A 51 year-old female patient presented with Hunt and Hess grade II underwent coil embolization and suffered from intractable clinical vasospasm resulting in death. Of these 20 patients, $17(85 \%)$ were available for clinical follow-up, at a mean of 32 months after treatment (range, 3 to 79 months), with 14 showing GOS 5 and three showing GOS 4.

\section{DISCUSSION}

Subtypes of SCA aneurysms did not differ significantly according to treatment modality. The mean or median diameter of SCA aneurysms according to classification was 1) lateral superior in 20 patients (mean, 6.5 $\mathrm{mm})$, 2) lateral horizontal in six (median, $8.0 \mathrm{~mm}$ ), and 3) lateral inferior in two (median, $5.7 \mathrm{~mm}$ ). One patient 
had a posterior type aneurysm, of diameter $2.0 \mathrm{~mm}$. Our classification of SCA aneurysms, which has no clinical implications at present, may be helpful in the selection of microcatheters and may be a factor prognostic for the endovascular treatment of SCA aneurysms.

According to a general consensus on SCA aneurysms, the presence of important perforating arteries and adjacent cranial nerves makes clipping of SCA aneurysms and complications occur as basilar apex aneurysms. However, perforators do not originate from the axillar of the $\mathrm{P} 1$ posterior cerebral artery (PCA) or the shoulder of the SCA, where the neck of an SCA aneurysm is dissected. $^{23)}$ Therefore, perforator infarctions, which may lead to morbidity at the basilar apex, may rarely develop during microsurgery of SCA aneurysms. We did not observe any perforator infarctions related to SCA aneurysms, although the number of patients undergoing microsurgery was small.

Since the proximal SCA is intimately related to cranial nerves III, IV, and $\mathrm{V},{ }^{19}$ ) aneurysms on the SCA may present with palsies of these nerves. ${ }^{17) 17)}$ One patient, with a $2.5 \mathrm{~mm}$ sized lateral-superior type of SCA aneurysm, showed third cranial nerve palsy, but this finding is relatively rare. ${ }^{177) 17)}$ Cranial nerve palsy may be affected by the direction or growth pattern of the aneurysm rather than its size. Complete or incomplete third nerve palsies developed in five patients who underwent microsurgery but recovered completely in all patients available for clinical follow-up.

Occlusion of the SCA appears to be well tolerated. ${ }^{4) 9)}$ One of the 33 SCA aneurysms was dissecting and was located in the S2-3 segment of the artery. Treatment of this aneurysm by complete trapping using a coil resulted in no neurological deficits. Collateral blood flow and a paucity of perforating arteries from the S1 and S2 segments may limit ischemic infarctions, usually resulting in good outcomes. ${ }^{4-6) 8) 18)}$

SCA aneurysms lie off the midline below the basilar bifurcation and are generally directed laterally. This orientation may improve visualization in the trajectory of the trans-sylvian approach and coil embolization of the aneurysms relative to basilar apex aneurysms, resulting in low procedural morbidity and mortality rates. Procedural morbidities related to SCA aneurysm were observed in one patient each treated with microsurgery or embolization and its rate was relatively low compared with rates in basilar apex aneurysms. ${ }^{12)}$

It is generally recommended that unruptured aneurysms $<7 \mathrm{~mm}$ in size with no associated symptoms be managed conservatively. ${ }^{3)}$ While a detailed natural history of unruptured SCA aneurysms has not been reported due to their rare incidence, it may differ from that of aneurysms at other locations. Many patients with SCA aneurysms and SAH have poor and grave clinical course. It may therefore be impossible to apply treatment guidelines for unruptured aneurysms of other locations to the treatment of SCA aneurysms. The mean diameter of the 22 SCA aneurysms accompanied by SAH was $7 \mathrm{~mm}$ (range, 1.8 to $15.6 \mathrm{~mm}$ ), whereas nine patients $(41.0 \%)$ had ruptured SCA aneurysms $<5 \mathrm{~mm}$. Poor clinical outcomes in three of four neurologically disabled patients resulted from initially poor clinical conditions. No procedural morbidities related to SCA aneurysms developed in any patient who underwent microsurgery or embolization of the non-ruptured aneurysms. One patient with a previous history of surgical clipping of another ruptured aneurysm and pre-aneurysmal dilatation in the junction between the BA and SCA on initial angiogram suffered from $\mathrm{SAH}$ four years after surgery. A conventional angiogram revealed the growth of the SCA aneurysm with rupture (diameter, $5.7 \mathrm{~mm}$ ). Active guideline of treatment or tight image follow-up may be necessary in the unruptured SCA aneurysms.

\section{CONCLUSIONS}

SCA aneurysms, which differ from basilar apex aneurysms, have peculiar characteristics, including a paucity of perforators, abundant collateral supplies and off the midline location, accompanied by relatively low proce- 
dural morbidity and no procedural mortality without treatment modalities. More active guidelines for the treatment of non-ruptured SCA aneurysms may be required based on our clinical experience of SCA aneurysms accompanied by SAH. Classification of SCA aneurysms may be a prognostic factor for endovascular treatment.

\section{REFERENCES}

1. Agostinis C, Caverni L, Moschini L, Rottoli MR, Foresti C. Paralysis of fourth cranial nerve due to superior-cerebellar artery aneurysm. Neurology. 1992 Feb;42(2):457-8.

2. Batjer HH, Samson DS. Causes of morbidity and mortality from surgery of aneurysms of the distal basilar artery. Neurosurgery. 1989 Dec;25(6):904-15; discussion 915-6.

3. Bederson JB, Awad IA, Wiebers DO, Piepgras D, Haley EC Jr, Brott T, et al. Recommendations for the management of patients with unruptured intracranial aneurysms: A Statement for healthcare professionals from the Stroke Council of the American Heart Association. Stroke. 2000 Nov;31(11):2742-50.

4. Chaloupka JC, Putman CM, Awad IA. Endovascular therapeutic approach to peripheral aneurysms of the superior cerebellar artery. AJNR Am J Neuroradiol. 1996 Aug; 17(7):1338-42.

5. Cloft HJ, Kallmes DF, Jensen ME, Lanzino G, Dion JE. Endovascular treatment of ruptured, peripheral cerebral aneurysms: parent artery occlusion with short Guglielmi detachable coils. AJNR Am J Neuroradiol. 1999 Feb; 20(2):308-10.

6. Cognard C, Weill A, Tovi M, Castaings L, Rey A, Moret J. Treatment of distal aneurysms of the cerebellar arteries by intraaneurysmal injection of glue. AJNR Am J Neuroradiol. 1999 May;20(5):780-4.

7. Collins TE, Mehalic TF, White TK, Pezzuti RT. Trochlear nerve palsy as the sole initial sign of an aneurysm of the superior cerebellar artery. Neurosurgery. 1992 Feb;30(2): 258-61.

8. Eckard DA, O'Boynick PL, McPherson CM, Eckard VR, Han P, Arnold P, et al. Coil occlusion of the parent artery for treatment of symptomatic peripheral intracranial aneurysms. AJNR Am J Neuroradiol. 2000 Jan;21(1):137-42.

9. Gacs G, Vinuela F, Fox AJ, Drake CG. Peripheral aneurysms of the cerebellar arteries. Review of 16 cases. J Neurosurg. 1983 Jan;58(1):63-8.

10. Haw C, Willinsky R, Agid R, TerBrugge K. The endovascular management of superior cerebellar artery aneurysms. Can J Neurol Sci. 2004 Feb;31(1):53-7.

11. Hunt WE, Hess RM. Surgical risk as related to time of intervention in the repair of intracranial aneurysms. J Neurosurg. 1968 Jan;28(1):14-20.

12. Jin SC, Ahn JS, Kwun BD, Kwon DH. Analysis of clinical and radiological outcomes in microsurgical and endovascular treatment of basilar apex aneurysms. J Korean Neurosurg Soc. 2009 Apr;45(4):224-30.

13. Lempert TE, Malek AM, Halbach VV, Phatouros CC, Meyers PM, Dowd CF, et al. Endovascular treatment of ruptured posterior circulation cerebral aneurysms. Clinical and angiographic outcomes. Stroke. 2000 Jan;31(1):100-10.

14. Lubicz B, Leclerc X, Gauvrit JY, Lejeune JP, Pruvo JP. Endovascular treatment of peripheral cerebellar artery aneurysms. AJNR Am J Neuroradiol. 2003 Jun-Jul;24(6): 1208-13.

15. Nagasawa S, Kobata H, Aoki J, Kawanishi M, Ohta T. A large thrombosed superior cerebellar artery aneurysm: a case report. Surg Neurol. 1996 Jan;45(1):36-8.

16. Peluso JP, van Rooij WJ, Sluzewski M, Beute GN. Distal aneurysms of cerebellar arteries: incidence, clinical presentation, and outcome of endovascular parent vessel occlusion. AJNR Am J Neuroradiol. 2007 Sep;28(8): 1573-8.

17. Peluso JP, van Rooij WJ, Sluzewski M, Beute GN. Superior cerebellar artery aneurysms: incidence, clinical presentation and midterm outcome of endovascular treatment. Neuroradiology. 2007 Sep;49(9):747-51.

18. Pierot L, Boulin A, Castaings L, Rey A, Moret J. Selective occlusion of basilar artery aneurysms using controlled detachable coils: report of 35 cases. Neurosurgery. 1996 May;38(5):948-53; discussion 953-4.

19. Rhoton AL Jr. The cerebellar arteries. Neurosurgery. 2000 Sep; 47(3):S29-68.

20. Roy D, Milot G, Raymond J. Endovascular treatment of unruptured aneurysms. Stroke. 2001 Sep;32(9):1998-2004. 
21. Roy D, Raymond J, Bouthillier A, Bojanowski MW, Moumdjian R, L'Esperance G. Endovascular treatment of ophthalmic segment aneurysms with Guglielmi detachable coils. AJNR Am J Neuroradiol. 1997 Aug;18(7):1207-15.

22. Sagoh M, Hirose Y, Murakami H, Mayanagi K. The outcome of early surgical management of ruptured posterior circulation aneurysms. Neurol Res. 1997 Aug;19(4):385-8.

23. Sanai N, Tarapore P, Lee AC, Lawton MT. The current role of microsurgery for posterior circulation aneurysms: a selective approach in the endovascular era. Neurosurgery. 2008 Jun;62(6):1236-49; discussion 1249-53.
24. Uda K, Murayama Y, Gobin YP, Duckwiler GR, Vinuela F. Endovascular treatment of basilar artery trunk aneurysms with Guglielmi detachable coils: clinical experience with 41 aneurysms in 39 patients. J Neurosurg. 2001 Oct;95(4): 624-32.

25. Ushikoshi S, Kikuchi Y, Houkin K, Miyasaka K, Abe H. Aggravation of brainstem symptoms caused by a large superior cerebellar artery aneurysm after embolization by Guglielmi detachable coils-case report. Neurol Med Chir (Tokyo). 1999 Jul;39(7):524-9. 